\title{
A comparison of ankle function between adults with and without Down syndrome
}

\author{
Hyang-Woon Yoon ${ }^{a}$, Tae-Ho Yu ${ }^{b}$, U-Hyeok Seo ${ }^{b}$, Jee-Won Lee ${ }^{b}$, So-Yeon Kim ${ }^{b}$, Soo-Jin Chung ${ }^{b}$, \\ Hye-Lim Chun ${ }^{c}$, Byoung-Hee Lee ${ }^{b}$ \\ ${ }^{a}$ Department of Physical Therapy, Hongseong Medical Center, Hongseong, Republic of Korea \\ ${ }^{b}$ Department of Physical Therapy, College of Health Science and Social Welfare, Sahmyook University, Seoul, Republic of Korea \\ ${ }^{\mathrm{c} D}$ Department of Physical Therapy, Health and Welfare Graduate School, Sahmyook University, Seoul, Republic of Korea
}

\begin{abstract}
Objective: The purpose of this study was to compare ankle function between adults with and without Down syndrome (DS). Design: Cross-sectional study.

Methods: Ten adults with DS and 18 without participated in this study and underwent manual muscle test (MMT), range of motion (ROM) assessment, star excursion balance test (SEBT), and functional movement screen (FMS). The tests were demonstrated to increase their accuracy and the actual measurements were assessed after one or two demonstrations. To minimize the standby time and fatigue, the travelled distance and measuring order were adjusted. To remove the influence of shoes on the measurements, the shoes were taken off and only socks were worn.

Results: Dorsal and plantar flexion MMTs of both ankles were significantly weaker and plantar flexion ROM of both ankles were significantly lower in adults with DS compared with those without $(p<0.05)$. However, dorsal flexion ROM of both ankles were not significantly different between them. There were significant differences in distances measured in all the directions (anterior, anterolateral, lateral, posterolateral, posterior, posteromedial, medial, and anteromedial directions) of SEBT ( $p<0.05)$. Significant differences were also demonstrated in the scores of hurdle step, inline lunge, shoulder mobility, and rotary stability among the seven items of FMS $(p<0.05)$.
\end{abstract}

Conclusions: To enhance the dynamic stability of adults with DS, it is necessary to improve ankle stability by strengthening the ankle dorsal and plantar flexors.

Key Words: Ankle, Down syndrome, Functional movement screen, Star excursion balance test

\section{Introduction}

Down syndrome (DS) is a chromosomal abnormality and can result in significant defects in cognitive and motor development [1]. Particularly, motor disturbances, such as abnormal gait and posture adjustments, slow responses to environmental changes, incoordination, and co-contraction of agonistic and antagonistic muscles have been demonstrated [2-4]. Such motor disturbances caused by DS lead to limited physical activities and exercise experience, and, thereby, cause a delay in sensory development, concepts of movement, and social development [5-8].

Balance is the ability to sustain the body's center of gravity within the base of support during minimal motion, and is a fundamental element of posture, gait, and exercise. Balance is adjusted following the integration of the afferent information sent from the somatosensory, visual, and vestibular systems in the central nervous system, which induces reflex control of the eyes and extremities [9]. Therefore, balance greatly influences independent living and safety of pa-

Received: 27 October, 2017 Revised: 12 November, 2017 Accepted: 12 November, 2017

Corresponding author: Byoung-Hee Lee

Department of Physical Therapy, College of Health Science and Social Welfare, Sahmyook University, 815 Hwarang-ro, Nowon-gu, Seoul 01795, Republic of Korea

Tel: 82-2-3399-1634 Fax: 82-2-3399-1639 E-mail: 3679@syu.ac.kr

(c) This is an Open-Access article distributed under the terms of the Creative Commons Attribution Non-Commercial License (http://creativecommons.org/licenses/ by-nc/4.0) which permits unrestricted non-commercial use, distribution, and reproduction in any medium, provided the original work is properly cited.

Copyright $@ 2017$ Korean Academy of Physical Therapy Rehabilitation Science 
tients with DS; it is the motor function that is very difficult for these individuals to acquire [10-12].

Balance is an important factor for the activities of daily living. In cases of balance-related disabilities, movement can be limited, which may have a negative impact on not only the participation in activities of daily living but also the quality of life $[13,14]$. The stability of the ankle joint is crucial to balance $[15,16]$. Although DS is known to result in congenitally poor ankle stability $[17,18]$, there are no studies that have precisely investigated this topic. The objectives of the present study were to conduct tests of ankle stability, such as the star excursion balance test (SEBT), functional movement screen (FMS), manual muscle test (MMT), and range of motion (ROM) assessment between adults with DS and those without to identify any significant differences, and use the results to propose guidelines of strengthening the muscles that will allow adults with DS to actively participate in their daily lives and social activities. Furthermore, another objective was to construct a database that can be used as the foundation for developing tests to evaluate the functional movements in adults with DS.

\section{Methods}

\section{Participants}

Twenty-eight participants were enrolled, which included 10 patients (aged 21-31 years) with DS and 18 students (aged 20-24 years) without DS from a university in Seoul. In the process of selecting the subjects, those with hearing and visual problems, musculoskeletal problems, ankle sprain, lower back pain, and history of major surgeries and diseases were excluded.

\section{Procedures}

MMT, ROM, SEBT, and FMS were conducted in all participants. Through survey and measurements, the general characteristics, such as sex, age, weight, and height were recorded. After the details of the study were explained, all participants provided their informed consent. The tests were demonstrated to increase their accuracy and the actual measurements were recorded after one or two demonstrations.

To minimize the standby time and fatigue, the measuring order and distance travelled were flexibly adjusted. To remove the influence of shoes on the measurements, they were taken off and only socks were worn.

\section{Measurement tools}

\section{MMT}

MMT is a test conducted to evaluate an individual's maximum muscular strength and has been the standard for measuring muscular strength of the overall body for a long time [19]. The contractile forces of the muscles involved are strongly related to the MMT score [20]. The extensor muscles of the ankle play an important role in gait [21].

\section{$R O M$}

The double-armed universal goniometer was used to measure the active ROM of the ankle joint. The basic posture for this set of tests was as follows: the participant was in the supine position, with the fixed arm positioned with the neutral position of the feet and the working arm positioned parallel to the line connecting the outer side of the heel and the end of the 5th toe.

\section{SEBT}

SEBT is a test conducted to evaluate the balance of the subjects by measuring the raised distance while having the subjects bear their body weight onto one leg and raise the other leg in 8 directions [22] (Figure 1). While this test is conducted, the body, the leg bearing the weight, and the nerves involved must be efficient to maintain movement and balance over the body's base of support [23]. SEBT has been clinically used to accomplish the purpose of research. Particularly, it is a very reliable and valid tool for measuring the dynamic balance ability in people with chronic ankle instability. To conduct SEBT, lines were drawn in 8 directions (anterior direction, anterolateral direction, lateral direction, posterolateral direction, posterior direction, posteromedial direction, medial direction, and anteromedial direction), and the participant stood at the center of the lines on one leg and

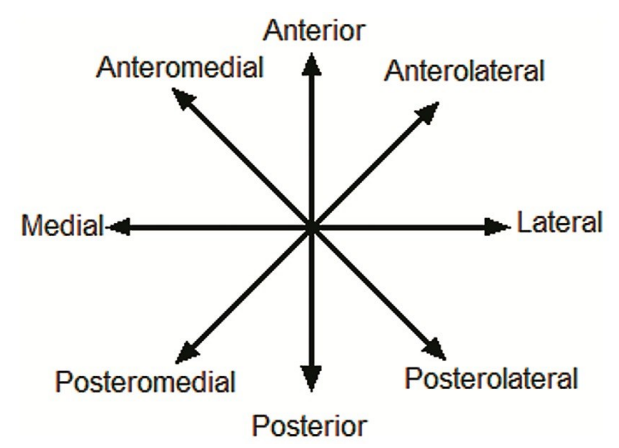

Figure 1. Star excursion balance test. 
raised the other leg as much as possible towards the lines in the clockwise fashion starting from the anterior direction [22].

\section{FMS}

FMS is a test conducted to evaluate the seven movements required for balance between mobility and stability (Figure 2). The seven movements are deep squat, hurdle step, inline lunge, shoulder mobility, active straight leg raise, trunk stability push-up, and quadruped rotary stability. In this test, a score ranging from 0 to 3 is assigned for each movement. The right side and left side are separately tested, and the lower score between the two is used as the final score. In FMS, all the functional disorders and causes of pain can be revealed through the seven basic movements. In case any pain is felt during the test, the test is stopped until it is resumed in the presence of a medical team. Additionally, it is the test that determines the time for patients undergoing rehabilitation to return to their daily lives $[24,25]$.

\section{Statistical analysis}

IBM SPSS Statistics ver. 20.0 (IBM Co., Armonk, NY, USA) was used to analyze the descriptive statistics and general characteristics, and the independent t-test was used to compare the data of the tests. The statistical significance level was sea at $\alpha=0.05$.

\section{Results}

\section{General characteristics of the participants}

The general characteristics of the participants are shown in Table 1. Of the 10 adults with DS, 3 were men (30.0\%) and 7 women $(70.0 \%)$, and of the 18 adults without DS, 11 were men (61.1\%) and 7 women (38.9\%). The mean age of the adults with DS was $25.00 \pm 2.944$ years whereas that of adults without DS was $21.44 \pm 1.580$ years. The mean height of the adults with DS was $153.40 \pm 7.675 \mathrm{~cm}$, whereas that of the adults without DS was $170.52 \pm 8.139 \mathrm{~cm}$. The mean weight of the adults with DS was $65.70 \pm 7.675 \mathrm{~kg}$, whereas that of
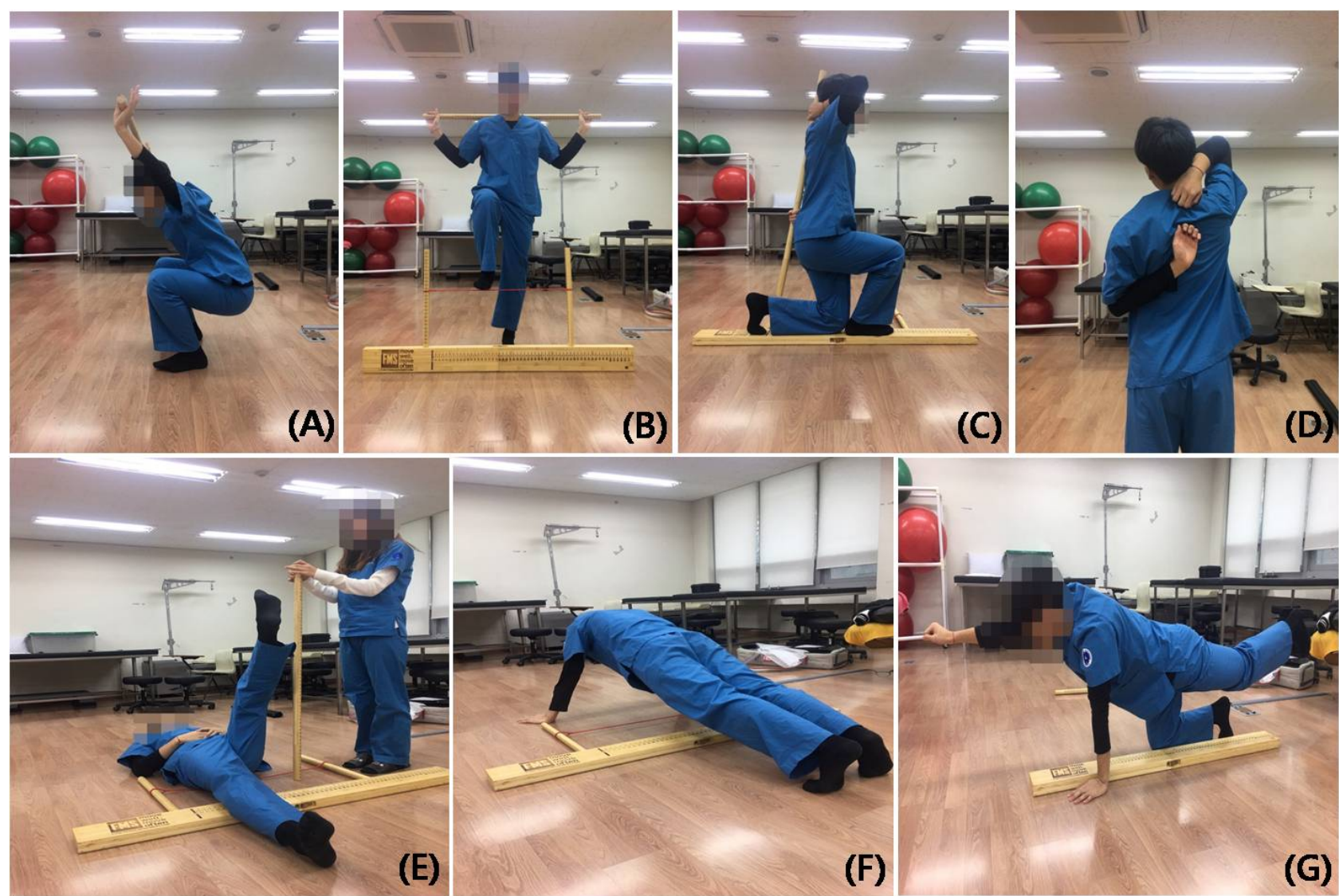

Figure 2. Functional movement screen. (A) Deep squat. (B) Hurdle step. (C) Inline lunge. (D) Shoulder mobility. (E) Active straight leg raise. (F) Trunk stability push-up. (G) Quadruped rotary stability. 
Table 1. General characteristics of subjects

$(\mathrm{N}=28)$

\begin{tabular}{lcc}
\hline Characteristic & Adults with DS (n=10) & Adults without DS (n=18) \\
\hline Male/female & $3(30.0) / 7(70.0)$ & $11(61.1) / 7(38.9)$ \\
Age (yr) & $25.00(2.944)$ & $21.44(1.580)$ \\
Height $(\mathrm{cm})$ & $153.40(7.675)$ & $170.52(8.139)$ \\
Weight $(\mathrm{kg})$ & $65.70(7.675)$ & $64.50(11.142)$
\end{tabular}

Values are presented as $\mathrm{n}(\%)$ or mean (SD).

DS: Down syndrome.

Table 2. Results of the MMTs

$(\mathrm{N}=28)$

\begin{tabular}{cccc}
\hline Variable & $\begin{array}{c}\text { Adults with } \\
\text { DS }(\mathrm{n}=10)\end{array}$ & $\begin{array}{c}\text { Adults without } \\
\text { DS }(\mathrm{n}=18)\end{array}$ & $\mathrm{t}(p)$ \\
\hline RD-MMT $(\mathrm{kg})$ & $4.15(3.097)$ & $19.36(3.982)$ & $10.424(<0.001)$ \\
RP-MMT (kg) & $3.42(2.140)$ & $25.92(12.546)$ & $5.581(<0.001)$ \\
LD-MMT (kg) & $4.36(3.610)$ & $19.69(7.659)$ & $5.938(<0.001)$ \\
LP-MMT (kg) & $3.84(2.308)$ & $24.98(13.079)$ & $5.027(<0.001)$ \\
\hline
\end{tabular}

Values are presented as mean (SD).

MMT: manual muscle test, DS: Down syndrome, RD-MMT: right dorsal MMT, RP-MMT: right plantar MMT, LD-MMT: left dorsal MMT, LP-MMT: left plantar MMT.

the adults without DS was $64.50 \pm 11.142 \mathrm{~kg}$.

MMT

The results of ankle MMT are shown in Table 2. Right dorsal (RD)-MMT was $4.15 \pm 3.097 \mathrm{~kg}$ in the adults with DS and $19.36 \pm 3.982 \mathrm{~kg}$ in those without $(p<0.05)$. Right plantar (RP)-MMT was $3.42 \pm 2.140 \mathrm{~kg}$ in the adults with DS and $25.92 \pm 12.546 \mathrm{~kg}$ in those without $(p<0.05)$. Left dorsal (LD)-MMT was $4.36 \pm 3.610 \mathrm{~kg}$ in the adults with DS and $19.69 \pm 7.659 \mathrm{~kg}$ in those without $(p<0.05)$. Left plantar (LP)-MMT was $3.84 \pm 2.308 \mathrm{~kg}$ in the adults with DS and $24.98 \pm 13.079 \mathrm{~kg}$ in those without $(p<0.05)$.

\section{ROM}

The ROM results of the ankle are demonstrated in Table 3. Right dorsiflexion ROM (RDFROM) was $36.32^{\circ} \pm 6.425^{\circ}$ in the adults with DS and $38.02^{\circ} \pm 8.840^{\circ}$ in those without, which was not significant $(p>0.05)$. Right plantar flexion ROM (RPFROM) was $22.36^{\circ} \pm 6.806^{\circ}$ in the adults with DS and $34.14^{\circ} \pm 4.637^{\circ}$ in those without $(p<0.05)$. Left dorsiflexion ROM (LDFROM) was $31.86^{\circ} \pm 8.870^{\circ}$ in the adults with DS and $38.41^{\circ} \pm 6.580^{\circ}$ in those without; the difference was not statistically significant ( $p>0.05)$. Left plantar flexion ROM (LPFROM) was $25.14^{\circ} \pm 6.054^{\circ}$ in the adults with DS and $37.43^{\circ} \pm 4.983^{\circ}$ in those without $(p<0.05)$.
Table 3. Results of ROM assessments

$(\mathrm{N}=28)$

\begin{tabular}{cccl}
\hline \multicolumn{1}{c}{ Variable } & $\begin{array}{c}\text { Adults with } \\
\text { DS }(\mathrm{n}=10)\end{array}$ & $\begin{array}{c}\text { Adults without } \\
\text { DS }(\mathrm{n}=18)\end{array}$ & \multicolumn{1}{c}{$\mathrm{t}(p)$} \\
\hline RDFROM $\left({ }^{\circ}\right)$ & $36.32(6.425)$ & $38.02(8.840)$ & $0.534(0.598)$ \\
RPFROM $\left({ }^{\circ}\right)$ & $22.36(6.806)$ & $34.14(4.637)$ & $5.444(<0.001)$ \\
LDFROM $\left({ }^{\circ}\right)$ & $31.86(8.870)$ & $38.41(6.580)$ & $2.229(0.350)$ \\
LPFROM ( $\left.{ }^{\circ}\right)$ & $25.14(6.054)$ & $37.43(4.983)$ & $5.796(<0.001)$ \\
\hline
\end{tabular}

Values are presented as mean (SD).

ROM: range of motion, DS: Down syndrome, RDFROM: right dorsiflexion ROM, RPFROM: right plantarflexion ROM, LDFROM: left dorsiflexion ROM, LPFROM: left plantarflexion ROM.

Table 4. Results of the SEBT

$(\mathrm{N}=28)$

\begin{tabular}{cccc}
\hline Variable & $\begin{array}{c}\text { Adults with } \\
\text { DS }(\mathrm{n}=10)\end{array}$ & $\begin{array}{c}\text { Adults without } \\
\text { DS }(\mathrm{n}=18)\end{array}$ & $\mathrm{t}(p)$ \\
\hline 1RSEBT $(\mathrm{cm})$ & $24.60(11.157)$ & $59.11(7.584)$ & $9.741(<0.001)$ \\
2RSEBT $(\mathrm{cm})$ & $32.40(13.882)$ & $64.22(7.727)$ & $7.846(<0.001)$ \\
3RSEBT $(\mathrm{cm})$ & $38.40(16.735)$ & $70.56(8.111)$ & $6.892(<0.001)$ \\
4RSEBT $(\mathrm{cm})$ & $39.30(18.500)$ & $75.00(9.899)$ & $6.700(<0.001)$ \\
5RSEBT $(\mathrm{cm})$ & $32.40(14.781)$ & $74.22(8.592)$ & $9.526(<0.001)$ \\
6RSEBT $(\mathrm{cm})$ & $20.80(19.257)$ & $62.44(9.978)$ & $7.591(<0.001)$ \\
7RSEBT $(\mathrm{cm})$ & $18.30(10.584)$ & $43.28(10.676)$ & $5.950(<0.001)$ \\
8RSEBT $(\mathrm{cm})$ & $24.20(12.977)$ & $49.00(9.337)$ & $5.856(<0.001)$ \\
1LSEBT $(\mathrm{cm})$ & $22.90(12.723)$ & $59.67(8.239)$ & $9.303(<0.001)$ \\
2LSEBT $(\mathrm{cm})$ & $32.20(13.481)$ & $65.00(7.754)$ & $8.226(<0.001)$ \\
3LSEBT $(\mathrm{cm})$ & $32.20(15.720)$ & $71.72(9.112)$ & $8.367(<0.001)$ \\
4LSEBT $(\mathrm{cm})$ & $32.00(15.463)$ & $73.89(10.781)$ & $8.429(<0.001)$ \\
5LSEBT $(\mathrm{cm})$ & $30.50(15.615)$ & $73.44(9.395)$ & $9.134(<0.001)$ \\
6LSEBT $(\mathrm{cm})$ & $7.80(18.725)$ & $63.27(10.250)$ & $10.091(<0.001)$ \\
7LSEBT $(\mathrm{cm})$ & $19.20(12.934)$ & $43.33(10.550)$ & $5.042(<0.001)$ \\
8LSEBT $(\mathrm{cm})$ & $24.00(14.205)$ & $49.39(7.868)$ & $6.129(<0.001)$ \\
\hline
\end{tabular}

Values are presented as mean (SD).

SEBT: star excursion balance test, DS: Down syndrome, 1RSEBT: right foot towards anterior, 2RSEBT: right foot towards anterolateral, 3RSEBT: right foot towards lateral, 4RSEBT: right foot towards posterolateral, 5RSEBT: right foot towards posterior, 6RSEBT: right foot towards posteromedial, 7RSEBT: right foot towards medial, 8RSEBT: right foot towards anteromedial, 1LSEBT: left foot towards anterior, 2LSEBT: left foot towards anterolateral, 3LSEBT: left foot towards lateral, 4LSEBT: left foot towards posterolateral, 5LSEBT: left foot towards posterior, 6LSEBT: left foot towards posteromedial, 7LSEBT: left foot towards medial, 8LSEBT: left foot towards anteromedial.

\section{SEBT}

SEBT results are shown in Table 4. Right foot towards the anterior direction on the SEBT (1RSEBT) was $24.60 \pm$ $11.157 \mathrm{~cm}$ in the adults with DS and $59.11 \pm 7.584 \mathrm{~cm}$ in those without $(p<0.05)$. Right foot towards the anterolateral direction (2RSEBT) was $32.40 \pm 13.882 \mathrm{~cm}$ in the adults with DS and $64.22 \pm 7.727 \mathrm{~cm}$ in those without $(p<0.05)$. Right 
foot towards the lateral direction (3RSEBT) was $38.40 \pm 16.735 \mathrm{~cm}$ in the adults with DS and $70.56 \pm 8.111 \mathrm{~cm}$ in those without $(p<0.05)$. Right foot towards the posterolateral direction (4RSEBT) was $39.30 \pm 18.500 \mathrm{~cm}$ in the adults with DS and $75.00 \pm 9.899 \mathrm{~cm}$ in those without $(p<0.05)$. Right foot towards the posterior direction (5RSEBT) was $32.40 \pm 14.781 \mathrm{~cm}$ in the adults with DS and $74.22 \pm 8.592 \mathrm{~cm}$ in those without $(p<0.05)$. The right foot towards the posteromedial direction (6RSEBT) was $20.80 \pm$ $19.257 \mathrm{~cm}$ for the adults with DS and $62.44 \pm 9.978 \mathrm{~cm}$ for the normal adults, and, therefore, a significant difference was shown $(p<0.05)$. The right foot towards the medial direction (7RSEBT) was $18.30 \pm 10.584 \mathrm{~cm}$ for the adults with DS and $43.28 \pm 10.676 \mathrm{~cm}$ for the normal adults, and, therefore, a significant difference was shown $(p<0.05)$. The right foot towards the anteromedial direction (8RSEBT) was $24.20 \pm 12.977 \mathrm{~cm}$ in the adults with DS and $49.00 \pm 9.337 \mathrm{~cm}$ in those without $(p<0.05)$. The left foot towards the anterior direction (1LSEBT) was $22.90 \pm 12.723 \mathrm{~cm}$ in the adults with DS and $59.67 \pm 8.239 \mathrm{~cm}$ in those without $(p<0.05)$. Left foot towards the anterolateral direction (2LSEBT) was $32.20 \pm 13.481 \mathrm{~cm}$ in the adults with DS and $65.00 \pm 7.754 \mathrm{~cm}$ in those without $(p<0.05)$. Left foot towards the lateral direction (3LSEBT) was $32.20 \pm 15.720 \mathrm{~cm}$ in the adults with DS and $71.72 \pm 9.112 \mathrm{~cm}$ in those without $(p<0.05)$. Left foot towards the posterolateral direction (4LSEBT) was $32.00 \pm 15.463 \mathrm{~cm}$ in the adults with DS and $73.89 \pm 10.781$ $\mathrm{cm}$ in those without $(p<0.05)$. Left foot towards the posterior direction (5LSEBT) was $30.50 \pm 15.615 \mathrm{~cm}$ in the adults with

Table 5. Results of FMS

$(\mathrm{N}=28)$

\begin{tabular}{cccl}
\hline Variables & $\begin{array}{c}\text { Adults with } \\
\text { DS }(\mathrm{n}=10)\end{array}$ & $\begin{array}{c}\text { Adults without } \\
\text { DS }(\mathrm{n}=18)\end{array}$ & $\mathrm{t}(p)$ \\
\hline FMS1 (score) & $2.00(0.943)$ & $2.61(0.608)$ & $2.091(0.460)$ \\
FMS2 (score) & $1.30(0.483)$ & $2.67(0.485)$ & $7.154(<0.001)$ \\
FMS3 (score) & $1.10(0.568)$ & $2.83(0.383)$ & $9.643(<0.001)$ \\
FMS4 (score) & $1.50(0.527)$ & $2.50(0.514)$ & $4.886(<0.001)$ \\
FMS5 (score) & $2.80(0.422)$ & $3.00(<0.001)$ & $2.044(0.510)$ \\
FMS6 (score) & $1.40(0.699)$ & $2.33(0.970)$ & $2.672(0.130)$ \\
FMS7 (score) & $1.30(0.483)$ & $1.94(0.236)$ & $4.775(<0.001)$ \\
FMS-total & $11.40(2.503)$ & $17.89(1.605)$ & $8.382(<0.001)$ \\
(score) & & & \\
\hline
\end{tabular}

Values are presented as mean (SD).

FMS: functional movement screen, DS: Down syndrome. The scores are representative of individual scores in the following components of FMS-FMS1: deep squat, FMS2: hurdle step, FMS3: inline lunge, FMS4: shoulder mobility, FMS5: active straight leg raise, FMS6: trunk stability push-up, FMS7: quadruped rotary stability.
DS and $73.44 \pm 9.395 \mathrm{~cm}$ in those without $(p<0.05)$. Left foot towards the posteromedial direction (6LSEBT) was $7.80 \pm 18.725 \mathrm{~cm}$ in the adults with DS and $63.27 \pm 10.250 \mathrm{~cm}$ in those without $(p<0.05)$. Left foot towards the medial direction (7LSEBT) was $19.20 \pm 12.934 \mathrm{~cm}$ in the adults with DS and $43.33 \pm 10.550 \mathrm{~cm}$ in those without $(p<0.05)$. Left foot towards the anteromedial direction (8LSEBT) was $24.00 \pm 14.205 \mathrm{~cm}$ in the adults with DS and $49.39 \pm 7.868 \mathrm{~cm}$ in those without $(p<0.05)$.

\section{FMS}

The results of FMS testing are shown in Table 5. The FMS score for the deep squat (FMS1) was $2.00 \pm 0.943$ in the adults with DS and $2.61 \pm 0.608$ in those without ( $p>0.05)$. The FMS score for the hurdle step (FMS2) was $1.30 \pm 0.483$ in the adults with DS and $2.67 \pm 0.485$ in those without $(p<0.05)$. The FMS score for the inline lunge (FMS3) was $1.10 \pm 0.568$ in the adults with DS and $2.83 \pm 0.383$ in those without $(p<0.05)$. The FMS score for shoulder mobility (FMS4) was $1.50 \pm 0.527$ in the adults with DS and $2.50 \pm$ 0.514 in those without $(p<0.05)$. The FMS score for the active straight leg raise (FMS5) was $2.80 \pm 0.422$ in the adults with DS and $3.00 \pm 0.000$ in those without $(p>0.05)$. The FMS score for trunk stability push-up (FMS6) was $1.40 \pm$ 0.699 in the adults with DS and $2.33 \pm 0.970$ in those without $(p>0.05)$. The FMS score for quadruped rotary stability (FMS7) was $1.30 \pm 0.483$ in the adults with DS and $1.94 \pm$ 0.236 in those without $(p<0.05)$. The overall FMS score was $11.40 \pm 2.503$ in the adults with DS and $17.89 \pm 1.605$ in those without $(p<0.05)$.

\section{Discussion}

Although there is general awareness that adults with DS have insufficient ankle stability, no research or study has focused on the ankle stability in them to calculate the precise results of tests. Therefore, we chose adults with and without DS as the subjects, compared the significant differences in ankle stability between them, and calculated the results. Based on the significant differences $(p<0.05)$ shown in the RPFROM, LPFROM, right dorsal flexor MMT, right plantar flexion MMT, left dorsal flexion MMT, and left plantar flexion MMT between the participants, we were able to quantitatively establish that the adults with DS demonstrated severe muscle weakness in comparison to those without DS. Based on the significant differences $(p<0.05)$ shown in the SEBT tests, we were able to confirm that the adults 
with DS demonstrated lower ankle stability in comparison to adults without DS. Based on the significant differences $(p<0.05)$ showed in the FMS tests, we were able to confirm that adults with DS demonstrated lower ankle stability and balance in comparison to adults without DS.

The adults with DS who showed poor results on the MMT also showed a tendency to fall the moment the test began. In this study, the inline lunge included in the FMS was conducted to observe the overall balance and muscular strength of the ankle. As a result, although the adults with DS did not fall, most of them failed to complete and gave up in the middle of the process. ROM was normal in adults with DS; therefore, their lack of muscular strength made it impossible for them to maintain their dynamic balance. This result are related to previous studies using ankle strengthening exercises as an intervention to improve dynamic balance. Balance and strength improvements are very important for adults with DS, since they can produce greater stability while performing activities of daily living or work related tasks and thus, decreasing the occurrence of accidents or falls resulting in a lower incidence of injuries [26]. Accordingly, to enhance the dynamic stability of adults with DS; at ankle level, it is necessary to improve their ankle stability through strengthening exercises of their ankle plantar and dorsal flexors.

\section{Conflict of Interest}

The authors declared no potential conflicts of interest with respect to the authorship and/or publication of this article.

\section{References}

1. Lloyd M, Burghardt A, Ulrich DA, Angulo-Barroso R. Physical activity and walking onset in infants with Down syndrome. Adapt Phys Activ Q 2010;27:1-16.

2. Savelsbergh GJP, van der Kamp J, Ledebt A, Planinsek T. Information-movement coupling in children with Down syndrome. In: Weeks DJ, Chua R, Elliott D, editors. Perceptualmotor behavior in Down syndrome. Champaign, IL: Human Kinetics; 2000. p. 251-76.

3. Webber A, Virji-Babul N, Edwards R, Lesperance M. Stiffness and postural stability in adults with Down syndrome. Exp Brain Res 2004;155:450-8.

4. Galli M, Rigoldi C, Mainardi L, Tenore N, Onorati P, Albertini G. Postural control in patients with Down syndrome. Disabil Rehabil 2008;30:1274-8.

5. Chapman RS, Hesketh LJ. Behavioral phenotype of individuals with Down syndrome. Ment Retard Dev Disabil Res Rev 2000;
6:84-95.

6. Pitetti K, Baynard T, Agiovlasitis S. Children and adolescents with Down syndrome, physical fitness and physical activity. J Sport Health Sci 2013;2:47-57.

7. Smith DS. Health care management of adults with Down syndrome. Am Fam Physician 2001;64:1031-8.

8. Bittles AH, Glasson EJ. Clinical, social, and ethical implications of changing life expectancy in Down syndrome. Dev Med Child Neurol 2004;46:282-6.

9. Lim KB, Na YM, Lee HJ, Joo SJ. Comparison of postural control measures between older and younger adults using balance master system. J Korean Acad Rehabil Med 2003;27:418-23.

10. Tsimaras VK, Fotiadou EG. Effect of training on the muscle strength and dynamic balance ability of adults with down syndrome. J Strength Cond Res 2004;18:343-7.

11. Lin HC, Wuang YP. Strength and agility training in adolescents with Down syndrome: a randomized controlled trial. Res Dev Disabil 2012;33:2236-44.

12. Cimolin V, Galli M, Grugni G, Vismara L, Precilios H, Albertini G, et al. Postural strategies in Prader-Willi and Down syndrome patients. Res Dev Disabil 2011;32:669-73.

13. Eyigor S, Karapolat H, Durmaz B, Ibisoglu U, Cakir S. A randomized controlled trial of Turkish folklore dance on the physical performance, balance, depression and quality of life in older women. Arch Gerontol Geriatr 2009;48:84-8.

14. Diener E, Suh EK. Measuring quality of life: economic, social and subjective indicators. Soc Indic Res 1997;40:189-216.

15. Spink MJ, Fotoohabadi MR, Wee E, Hill KD, Lord SR, Menz HB. Foot and ankle strength, range of motion, posture, and deformity are associated with balance and functional ability in older adults. Arch Phys Med Rehabil 2011;92:68-75.

16. Cioni M, Cocilovo A, Rossi F, Paci D, Valle MS. Analysis of ankle kinetics during walking in individuals with Down syndrome. Am J Ment Retard 2001;106:470-8.

17. Han SJ, Lee SG, Park SB, Oh KY, Lee KH. Effect of unilateral ankle brace on postural sway and limb load asymmetry. J Korean Acad Rehabil Med 2006;30:508-12.

18. Galli M, Rigoldi C, Brunner R, Virji-Babul N, Giorgio A. Joint stiffness and gait pattern evaluation in children with Down syndrome. Gait Posture 2008;28:502-6.

19. Lunsford BR, Perry J. The standing heel-rise test for ankle plantar flexion: criterion for normal. Phys Ther 1995;75:694-8.

20. Perry J, Ireland ML, Gronley J, Hoffer MM. Predictive value of manual muscle testing and gait analysis in normal ankles by dynamic electromyography. Foot Ankle 1986;6:254-9.

21. Kesar TM, Perumal R, Reisman DS, Jancosko A, Rudolph KS, Higginson JS, et al. Functional electrical stimulation of ankle plantarflexor and dorsiflexor muscles: effects on poststroke gait. Stroke 2009;40:3821-7.

22. Gribble PA, Hertel J. Considerations for normalizing measures of the star excursion balance test. Meas Phys Educ Exerc Sci 2004; 7:89-100.

23. Earl JE, Hertel J. Lower-extremity muscle activation during the star excursion balance tests. J Sport Rehabil 2001;10:93-104.

24. Frost DM, Beach TA, Callaghan JP, McGill SM. Using the functional movement screen ${ }^{\mathrm{TM}}$ to evaluate the effectiveness of training. J Strength Cond Res 2012;26:1620-30.

25. Parchmann CJ, McBride JM. Relationship between functional 
movement screen and athletic performance. J Strength Cond Res 2011;25:3378-84.

26. Hinckson EA, Curtis A. Measuring physical activity in children and youth living with intellectual disabilities: a systematic review. Res Dev Disabil 2013;34:72-86. 